\title{
Effect Of Geometry Of The Broad Crested Weir On The Dimensions Of The Downstream Apron
}

\author{
Kassem S. El-Alfy* and Moustafa A. El-Enany** \\ *, ** Assistant Prof., Dept. of Civil Eng., Faculty of Engineering, \\ Menoufia University, Shebin El-Kom, Egypt.
}

\begin{abstract}
The objective of this study is to investigate the effect of the geometry of the broad crested weir, (crest height, crest width, top surface slope, top surface roughness, corners radius, and crest contraction ratio), on the predicted apron length (L) and depth (D).

The experimental work has been carried out using a beech models placed in an open rectangular flume under different values of discharge. These models are divided to six categories to study the effect of the aforementioned parameters. Also, one model of cach category is built-up with the experimental predicted apron dimensions and reexamined against the D.S. scour at the same conditions.

From the experimental results of the present investigation, it is found that there is a general increase in the apron length and depth with thi corresponding increase in weir crest height. It is also found that there is an inverse proportionality between the crest width $(\delta)$ and both of the apron length and depth. The increase of the crest angle slope in direction of flow $(\theta)$ results in increasing both of the length and the depth of the apron, however the apron depth is more sensitive than its length. The increase of the contraction ratio increases both of the depth and the length of the downstream apron. It is found that the crest
\end{abstract}

Maunseript Received From Dr. Kassem S. El-Ally and Dr. Moustafa A. El-Enany. on 14/10/1908. Accepted on : 26/10/1998.

Engrineering Researcth Bulletin, Vol. 22, No. 1, 1999.

Minufiya University, Faculty of Engineering, Shebin EI-Kom, EGYPT, iss $1110-1180$ 
surface roughness has a little effect on the variation of the apron length and depth. It is also noticed that the increase of the weir

corners radius increases the depth of the apron at rate greater than that of the increase of its length. The examination of the models with the experimental predicted apron dimensions shows that the scour occurs downstream the predicted apron is very small compared with that occurs before the construction of the apron, which increases the safety factors against piping, overturning, etc. The equations describing the relationships between the predicted apron dimensions and the different geometry properties of the broad crested weir are also developed.

\section{Introduction}

The flow downstream weirs includes two types of vortex (of horizontal axis), the first is the Positive vortex which moves in clockwise direction and the second is the negative vortex moves in anticlokwise direction. The positive vortex has a bad effect on the bed particles. So to overcome this risk, it is required to construct a downstream apron with a suitable length (L) and depth (D) to return the flow velocity distribution to the normal distribution.

where

L Apron length.

D vertical distance between the D.S. normal bed level and the top surface of the apron.

Some empirical relations had been developed to compute the scour length, which should be covered by the solid apron. In 1943, Morris and Johnson concluded, from their laboratory study in California Technology Institute, that the apron length can be computed from the following relation:-

$\mathrm{L}=\mathrm{C} \sqrt{Y H}$

Where

L Apron length 
C Coefficient

Y The crest height (weir height)

$\mathrm{H}$ Head over weir

$C=2.5+1.1 \frac{H}{Y}+0.7\left[\frac{H}{Y}\right]^{3}$

where, the above equation is restricted for $\mathrm{H} / \mathrm{Y}>1$

They also stated that the existence of the apron do not prevent totally the formation of the scour hole, so the main aim of the designer is to minimize that hole and to dislodge it away from the weir structure as possible.

Rand and Moor proposed the following relation to compute the length of the apron, provided that no stilling basin;

$$
\begin{aligned}
& \frac{X_{1}}{Y}=\left[\frac{H}{Y}\right]^{0 .(k)} \\
& X_{2}=6.90\left(Y_{1}-Y_{2}\right)
\end{aligned}
$$

Where

H Head over weir

$x_{1} \quad$ Apron length between the end of weir and first depth of the hydraulic jump

$x_{2} \quad$ Length of the hydraulic jump.

In 1912 Bligh developed an imperial relation to compute the scour length D.S. weirs.

$$
L_{s}=0.61 C \sqrt{H_{s}}
$$

where

$L_{s} \quad$ Scour length in meter

C Coefficient depends on the soil type

$H_{s} \quad$ Maximum head producing scour = u.s.w.d. - critical depth.

Also, Bligh deduced the following formula that compute the length of the apron from the existing structures which insure durability with time. So many researchers saw that Bligh equation can be used in the predesign of the structure where the finial design depends on the laboratory models study. 


$$
L_{2}=3 C \sqrt{\frac{Z_{1}}{3} \sqrt{\frac{q}{7}}}
$$

$$
L_{1}=1.2 C \sqrt{\frac{Z_{1}}{3.9}}
$$

where

$L_{1} \quad$ Length of solid apron

$L_{2} \quad$ Total length of the apron (solid and riprap)

$Z_{1} \quad$ Difference between the water level in U.S. and D.S.

q Discharge per unite length of the weir crest

C Coefficient

\section{LABORATORY WORK}

The experiments are carried in laboratory of the Irrigation works design in Civil Engineering Department, Menoufia University. The experimental set-up consists basically of a horizontal channel of rectangular cross-section, $18.0 \mathrm{~m}$. long, $1.20 \mathrm{~m}$. width and $0.60 \mathrm{~m}$. depth. A brick flume of $8.0 \mathrm{~m}$. long, $0.2 \mathrm{~m}$ wide and $0.6 \mathrm{~m}$ depth is built-up through the main channel. The flume sides are lined with adequor material to prevent leakage of water. The flume is provided by an upstream tank of $1.0 \times 1.0 \times 1.0 \mathrm{~m}$ and a downstream tail gate to control the downstream water depth. The flow in the flume is recirculating through a centrifugal pump of $60 \mathrm{litcr} / \mathrm{sec}$ discharge. The levels are measured by Vernier point gage and the flow rates are controlled with valves and measured with the digital current meter. The precautions are considered at the upstream tank to reducc water level disturbance. The beech weir models with the required properties are fixed perpendicularly to the centerline of the flume.

\section{Experiments Procedure}

The experiments are carried out using the different weir models described later at the case of canal refilling. Different values of discharge of 15.0, 22.0, 36 and 41.0 liter/sec are used. The bed material used in experiments is coarse sand of $d_{50}=1.2$ $\mathrm{mm}$. The following procedure is followed for each of the performed runs: 
1- A certain discharge is regulated using the intake valve of the feeding pipe-line.

2- The weir model with specified characteristics is fixed carefully on the bed of the flume perpendicular to its center line.

3- The sand bed downstream the weir model is compacted carefully and checked to be horizontal.

4- The zero reading of the movable point gauge is adjusted so that it measures the depth of scour downstream the weir, the crest level and water level upstream the model.

5- The pump is switched on.

6- After the steady state condition of the movable bed downstream the weir model is attained, the pump is switched off and the following parameters are measured:

a- The water head on weir crest at a distance of about 80 $\mathrm{cm}$ upstream the weir model.

b- The scour length and depth of the hole formed downstream the weir model, which should be covered by the apron.

7- Steps ( 2 to 6 ) are repeated for each value of discharge.

8- A solid apron of length and depth resulted from the last run of each property is built-up downstream the weir model and steps ( 1 to 6 ) for the same run is repeated under the aforementioned conditions.

For the experimental work the following effects are studied:-

\section{A-Influence of crest height}

Influence of the weir crest height on the broad crested weir apron dimensions is studied through seven models manufactured from beech and painted with nonpermeable material. The weir models are of constant crest length of 0.20 $\mathrm{m}$., constant crest width of $0.50 \mathrm{~m}$., and smooth horizontal crest surface. Both of the upstrcam and downstream faces of the weir are vertical. The different values of crest height are 0.20 , $0.225,0.25,0.275,0.30,0325$, and $0.35 \mathrm{~m}$., respectively.

\section{B-Influence of crest width}

The values of the weir crest width $(\delta)$ are selected provided that $2 H<\delta<8 H$. The models used in this study are of crest length (b) of $0.20 \mathrm{~m}$, crest height of $0.20 \mathrm{~m}$, and variable crest width of $0.35,0.45,0.50,0.55,0.60$, and $0.70 \mathrm{~m}$. The 
models are of vertical U.S. and D.S. faces and horizontal smooth surface.

\section{C-Influence of crest slope}

In this case, the upstream height of models is $0.20 \mathrm{~m}$., while the downstream height is variable depending on the crest slope in direction of flow. The weir crest width is $0.60 \mathrm{~m}$. at the horizontal projection with smooth surface. The various values of the crest slope in direction of flow are $0,3.0,5.0,8.0,10,15$, and 20 degree, respectively. Both of the flow characteristics and the bed properties are unchanged.

\section{D- Influence of crest contraction ratio}

To determine the effect of crest contraction ratio, different values of crest length are considered. The different values of contraction ratio are applied for models of crest height of 0.20 $\mathrm{m}$., crest width of $0.60 \mathrm{~m}$. and horizontal smooth crest surface. both the upstream and downstream weir faces are vertical. The contraction ratio considered are $0,0.1,0.15,0.2,0.25$, and 0.3 .

\section{$\mathbb{E}$ - Influence of crest surface friction}

The roughened crest surfaces are prepared for the present investigation. This carried out by the coating of rectangular steel plates of dimensions $0.2 \times 0.6 \mathrm{~m}$, with a thin film of epoxy and covering them with coarse sand or gravel of different sizes which have been previously separated by sieving. The steel plates are fixed on the crest of weir models. Five artificially roughened crest surfaces are prepared for the experiments. Each plate has onc uniformly sizes of the roughness.

Four different sizes of gravel and one sizes of coarse sand are used to study the effect of the crest surface roughness on the weir apron dimensions. The gravel sizes are as follows: the first size retained on the $2 \mathrm{~mm}$ square mesh screen but passed through the $4 \mathrm{~mm}$ square mesh, the second size retained on the $4 \mathrm{~mm}$ square mesh screen but passed through the 4.75 $\mathrm{mm}$ square mesh, the third size retained on the $4.75 \mathrm{~mm}$ square mesh screen but passed through the $9.5 \mathrm{~mm}$ square mesh, the fourth size retained on the $12.5 \mathrm{~mm}$ square mesh screen but passed through the $19 \mathrm{~mm}$ square mesh. The coarse sand is retained on $1.0 \mathrm{~mm}$ square mesh screen but passed through the 2 
mm square mesh screen. The equivalent heights of rough elements are $0.46,1.15,2.64,4.83,8.29 \mathrm{~mm}$.

\section{F- Effect of weir corners radius}

The effect of both of the upstream and downstream corners radius is studied through six models of crest height of $0.20 \mathrm{~m}$, crest length of $0.20 \mathrm{~m}$, crest width of $0.60 \mathrm{~m}$, and horizontal smooth crest surface. The corners radius considered in this study are $0,0.01,0.015,0.02,0.025,0.03,0.035$, and 0.04 m., respectively.

\section{ANALYSIS AND DISCUSSION OF THE RESULTS}

The predicted apron length and depth downstream the broad crested weir are determined for aforementioned geometric properties under different values of discharge. The experimental results of the present investigation are graphically represented in this section. The results include the relationships between the apron characteristics (length and depth) and the different properties of the broad crested weir.

Figures (1-a) and (1-b) illustrate the variation of both of the apron length and depth, respectively, versus the weir crest height. It should be pointed out herein that the apron length and depth increase with the increase of weir height, and the following relationships are developed.

$$
\begin{aligned}
& L=29.1 Y^{0.555} q^{0.535} \\
& D=1.27 Y^{0.356} q^{0.335}
\end{aligned}
$$

In different cases of discharge, the increase of the crest height by $75 \%$ increases the apron length by an average value of $34 \%$, and the apron depth by an average value of $35 \%$. This is due to the increase in weir crest height increases the total energy of the flowing water and causes the water flowing as a jet, which requires a long apron to return the velocity curve to a normal distribution. Also the deep apron is required because the water over the apron works as a cushion dissipate the overflow jet energy.

Figures (2-a) and (2-b), show the relationships between the crest width $(\delta)$ and both of the apron length and depth, 
respectively. The figures show a general decrease in both the length and the depth of the predicted apron with the corresponding increase in crest width $(\delta)$ for the different selected values of the discharge. The results show that the increase in crest width by $100 \%$ decreases the required apron length and depth by an average values of $0.53 \%$ and $0.58 \%$ ,respectively, for the different values of discharge. This can be interpreted from the measurements of water along the crest width, as the crest width increases the water depth over the crest weir increases. The increase of the water depth with constant discharge decreases the water velocity, which decreases both the inflowing water momentum and kinetic energy, and hence both the apron length and depth decrease. The relationships controlling this criteria take the following forms:

$$
\begin{aligned}
& L=26.7 \delta^{0.9014} q^{0.562} \\
& D=1.32 \delta^{0.594} q^{0.378}
\end{aligned}
$$

Figures (3-a) and (3-b) illustrate the relationships between the crest slope angle in direction of flow and both of the apron length and depth, respectively. It is shown that the apron depth is more sensitive for the crest slope in direction of flow than the crest length. The increase of crest angle from $3^{\circ}$ to $20^{\circ}$ increases the required apron depth by an average value $125 \%$, while the required apron length increases by $109 \%$. This can be explained as the increase of crest slope angle in direction of flow results in increasing the flow velocity as a whole, but the vertical component of the velocity increases more than the horizontal component, which require a long and deeper apron. The. following relationships are developed:

$$
\begin{aligned}
& L=11.1 S^{0.236} q^{0.344} \\
& D=1.41 S^{0.217} q^{0.23}
\end{aligned}
$$

Figures (4-a) and (4-b) show the influence of the crest contraction ratio on both of the required length and depth of the apron, respectively. From the results it is found that the increase of the contraction ratio increases both of the required length and depth of the apron. The increase of contraction ratio from 0.1 to 
0.3 increases the required length of the apron by an average value of $98 \%$ for the different cases of discharge, while the required depth increases by $88.8 \%$. This can be attributed form the measurements of the upstream head on the weir, where it is found that the decrease of the crest length (b) increase the water head on the weir, which results in increasing the inflowing water velocity. The increase of velocity increases both the momentum and kinetic energy of the flowing water which require more apron length and deeper water cushion. The equations describing these relationships are;

$$
\begin{aligned}
& L=8.71 C r^{0.1117} q^{0.397} \\
& D=1.45 C r^{0.305} q^{0.382}
\end{aligned}
$$

From Figures (5-a) and (5-b), which represent the relationships between the equivalent roughness height and the required apron length and depth, it is seen that as the equivalent roughness height increases the predicted apron length and depth decrease. The figures show that the increase of relative roughness height from 0.00046 to $0.0084 \mathrm{~m}$. decreases the required apron length by $44 \%$, and depth by $35 \%$, respectively. This can be explained due to the fact that the increase in friction factor increases the total energy loss, hence the inflowing water velocity requires a small length to return to the normal velocity distribution and small depth water cushion to dissipate the inflowing water energy. It is worth mentioning that the influence of relative roughness height is quite appreciable at high values of discharge, where the energy loss is proportional with flow velocity. The relationships between the roughness height and both of the predicted apron length and depth take the following forms:

$$
\begin{aligned}
& L=3.75 f^{0.0198} q^{0.276} \\
& D=1.71 f^{0.0446} q^{0.484}
\end{aligned}
$$

Figures (6-a) and (6-b) illustrate the effect of both the upstream and downstream corners radius of the broad crested weir on the predicted apron length and depth. The increase of radius from 0.0 to $0.04 \mathrm{~m}$. increases the required apron length and depth by an average values of $117.5 \%$ and $101.6 \%$, 
respectively. This can be explained as the increase of upstream radius improve the flow characteristics, which reduces the energy loss, and the increase of the downstream corner radius directs the streamlines near the end of the weir and approximately perpendicular on the canal bed. It is also noticed that the effect of the corners radius is more obvious with the high values of discharge. This relations lead to the following equations:

$$
\begin{aligned}
& L=19.43 r^{0.2113} q^{0.419} \\
& D=1.47 r^{0.17} q^{0.282}
\end{aligned}
$$

The reexamination of the selected models with constructing a solid apron with the predicted dimensions resulted from the experiments shows that the scour occurs downstream the apron is very small compared with that occurred before the construction of the apron. This can be explained due to the fact that the water depth over the apron, which equal to the apron depth works as a cushion dissipates a big part of the inflowing water energy and the apron length returns the velocity distribution to a normal distribution.

\section{Conclusion}

This research concerns with the determination of the effect of the geometry of the broad crested weir on both of the predicted length and depth of the downstream apron. From the experimental results of the present investigation, it can be concluded the following:-

1- As the weir crest height over the canal bed increase both of the predicted apron length and depth should be increased.

2 - It is found that there is an inverse proportionality between the crest width, $(\delta)$ and both the apron length and depth.

3- The increase of the crest slope angle in direction of flow results in increasing both the length and depth of the apron, however the apron depth is more sensitive than its length.

4- The increase of the contraction ratio increases both the depth and length of the downstream apron. 
5- The increase of the equivalent roughness height of the crest decreases the apron length by a small rate.

6- The crest surface roughness is less effective on the apron dimensions compared with the other geometry of the weir.

7- Also, it is noticed form the experimental measurements that the increase of both the upstream and downstream corner radius require a long and deep apron, however the apron length is more sensitive to the change in corners radius than its depth.

8- The construction of the downstream apron with the predicted length and depth under different flow conciitions results in decreasing the scour downstream the structure by a significant degree.

\section{References}

1- A. M. Yassin, M. A. Ashour, S. T. El-Attar, A. M. Badr "Scour length downstream the clear overfall weirs at the drop", Bulletin of the Faculty of Engineer, Assiut University, Vol. 23, No.2, July, 1995.

2- Bligh, "The practical design of irrigation works", London, Constable, 1912.

3- B.T. Morris and D.C. Johnson, "Hydraulic design of drop structures for gully control", Trans. ASCE., 1943.

4- W. Rand, "Flow geometry at straight drop spillways", proc. ASCE., vol. 81, (Sept. 1955), no 791.

5- Ven-Te-Chow, "Open Channel Hydraulics", Mc.Graw Hill Inc., 1955.

\section{Symbols}

C coefficient depends on the soil type

$C_{r} \quad$ crest contraction ratio

D apron depth

f equivalent roughness of the crest surface

$\mathrm{H}$ head over weir

$H_{s} \quad$ maximum head producing scour = u.s.w.d. - critical depth

$L$ apron length.

$L_{s} \quad$ scour length in meter

$L_{1} \quad$ length of solid apron 
$L_{2} \quad$ total length of the apron (solid and riprap)

$r \quad$ weir crest corners

q discharge por unite length of the weir crest

$S$ crest slope in direction of flow

$x_{1} \quad$ apron length up to the first depth of the hydraulic jump

$x_{2} \quad$ length of the hydraulic jump

$Y$ the crest height (weir height)

$Z_{1}$ difference between the water level in U.S. and D.S.

$d_{50}$ the median diameter of the bed soil

$\delta \quad$ crest width in meter (wcir width)

$\theta$ angle crest slope in direction of flow (radin)

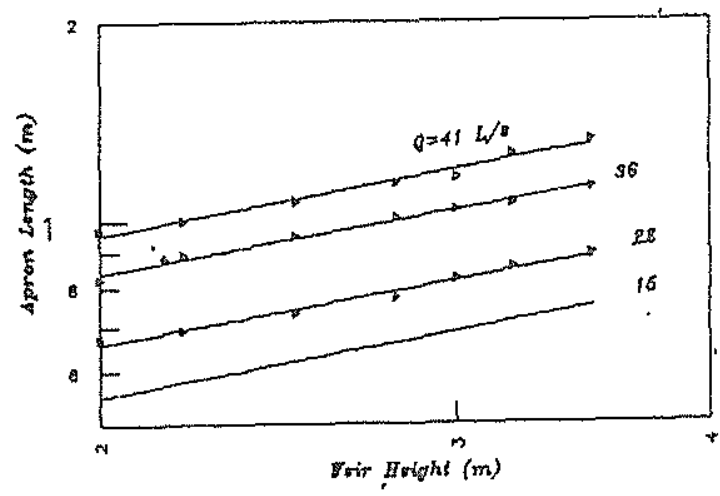

Fig.(:-a) Relationship between Apron length versus orest hoight

and $(Q)$ to a third dimension

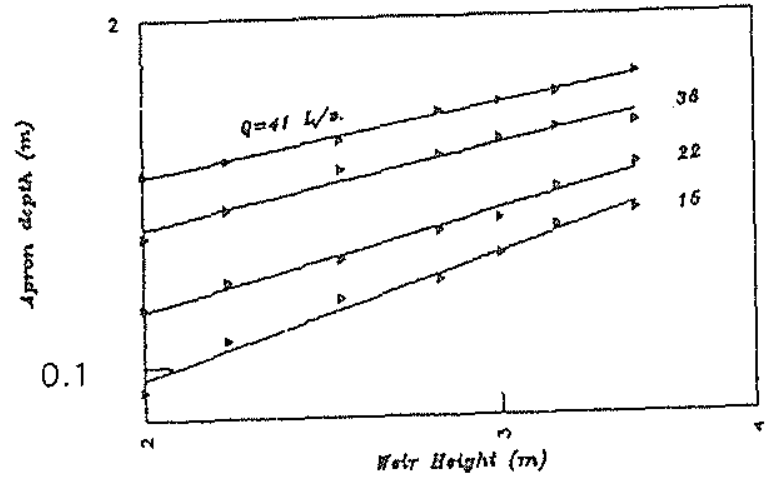

Fig.(1-b) Relationship between Apron length versus orest height

and $(Q)$ as a third dimansion 


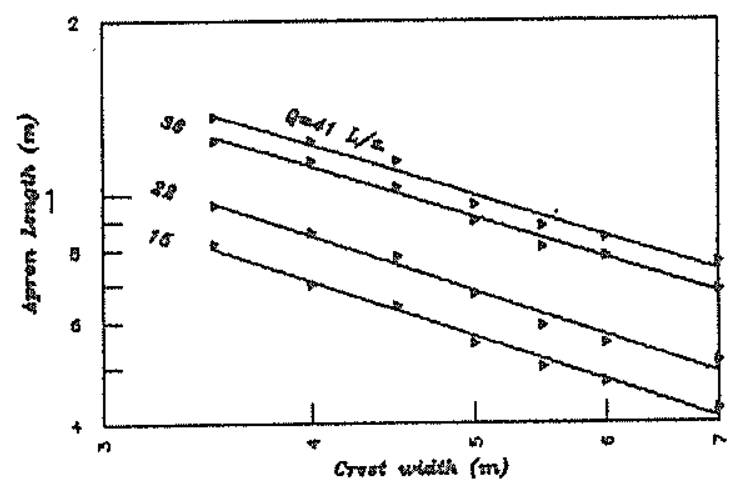
Fig.(2-a) Relationship betwen Apron langth
verens orest hoight

and (0) as a third atimonsion

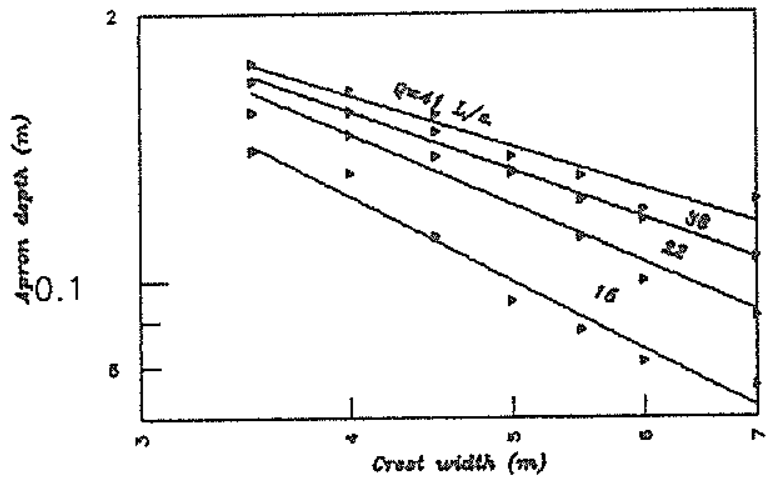

Pig.(2-b) Ralationship bstueen Apron lsngth vereus orest hoight and (a) as a third dimansion

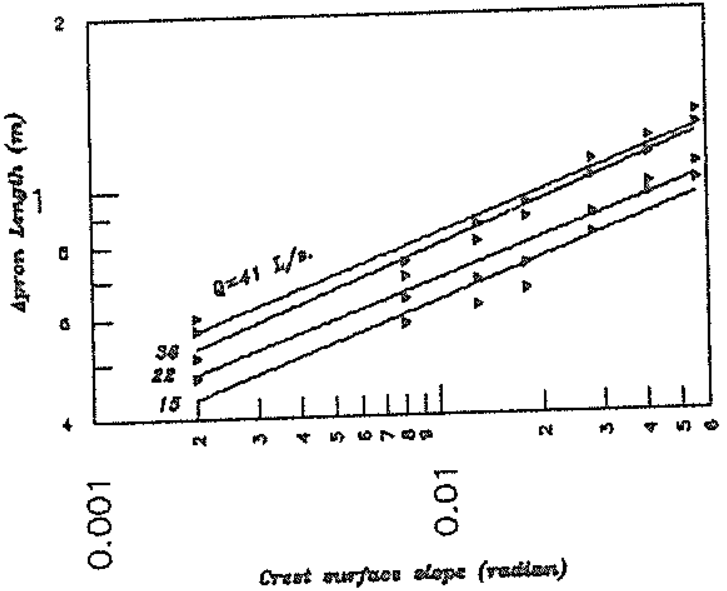

Fig.(3-a) Relationship betwaen Apron length versus orest haight

and (Q) on a third dimsnsion 


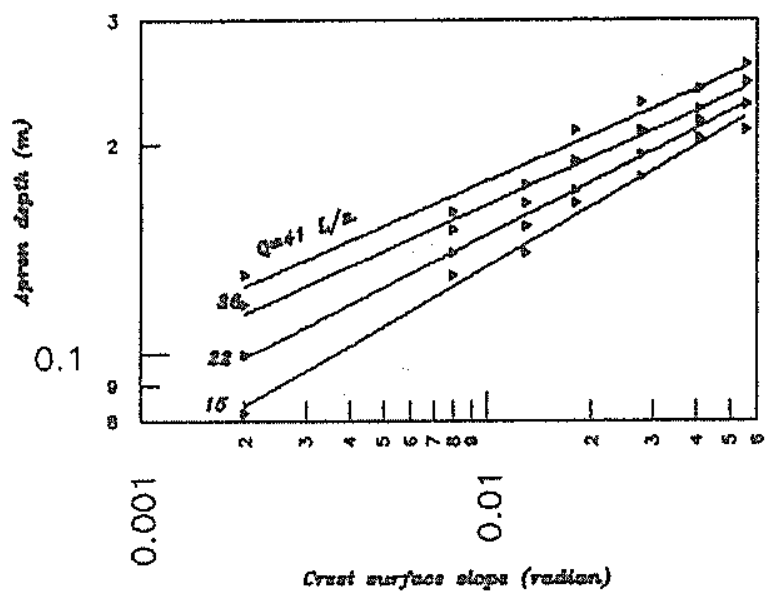

Fig.(3-b) Relationahip botudeen Apron langth versus oreat hoight

and (Q) a third dimsnsion

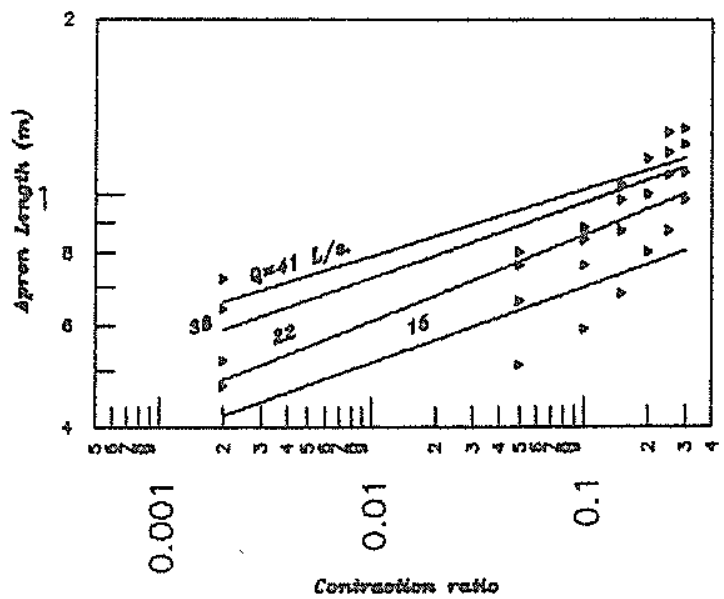

Pig.(4-a) Relationship between Apron length versuss orest hoight and (Q) as a third timsngion

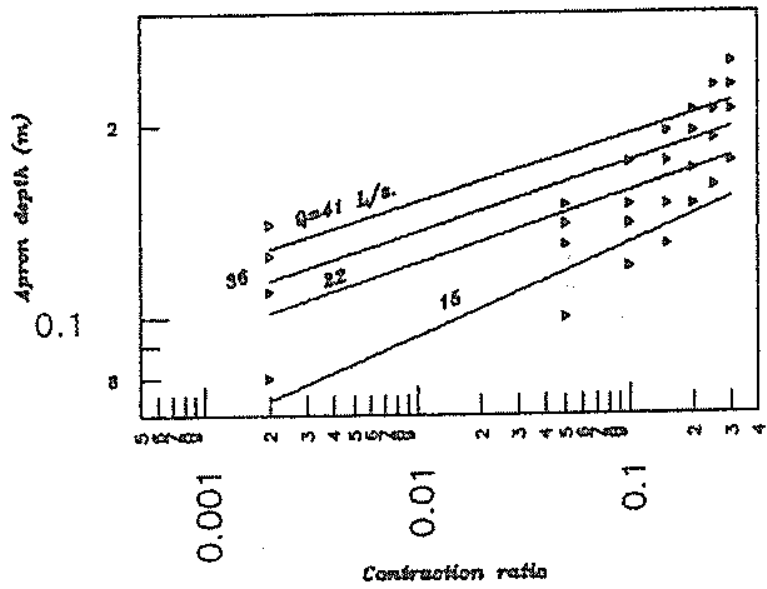

Fig.(4-b) Rolationship behusen Apron length versus orest hoight

and $(Q)$ as a third dimanotion 


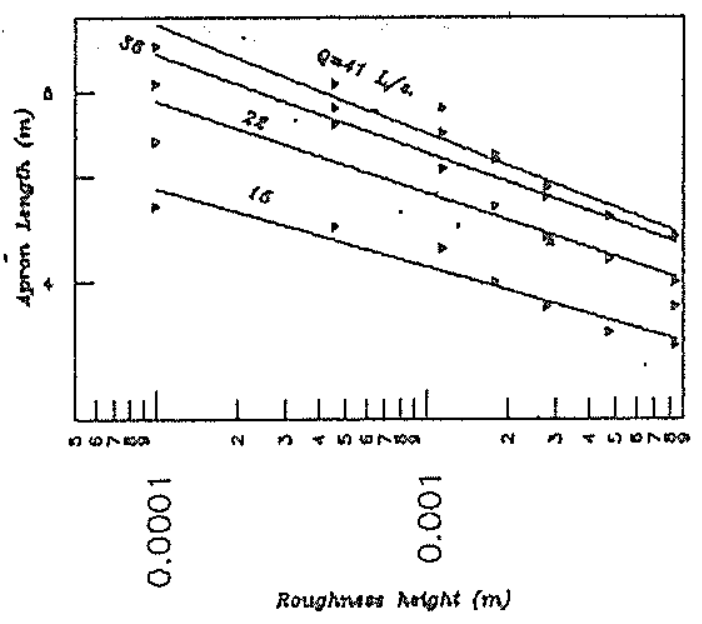
Fig. (5-a) Relationship between Apron length
versus orest hoight and $(Q)$ as a third dimension.

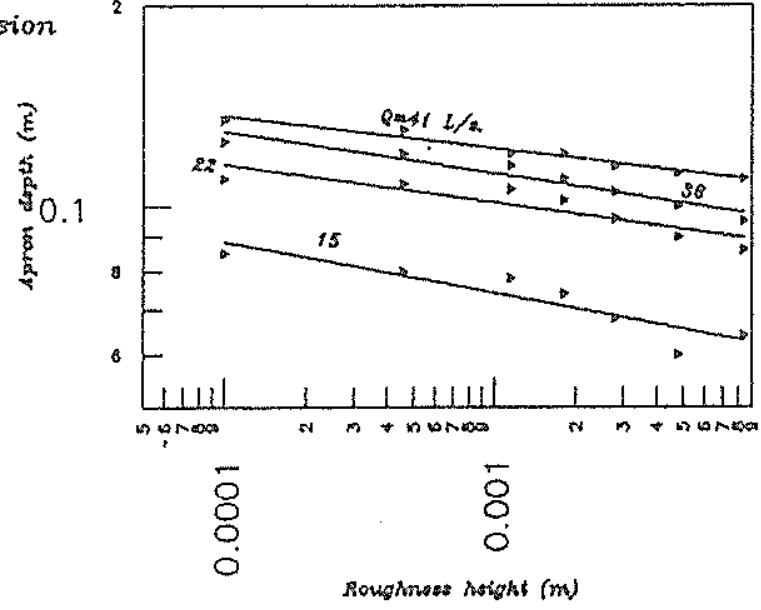

Fig.(5-b) Relationship between Apron length verencs orest hoight and $(Q)$ as a third dimension

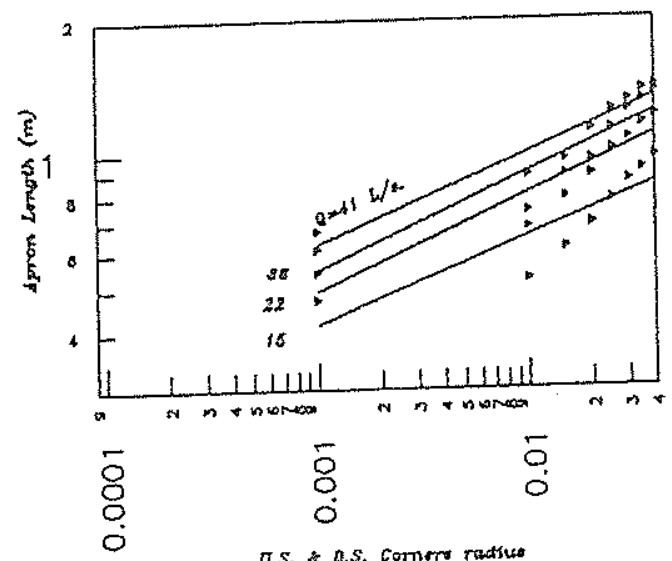

Fig. $(6-a)$ Relationship batween Apron length verous oreat hoight and $(Q)$ as a third dimension

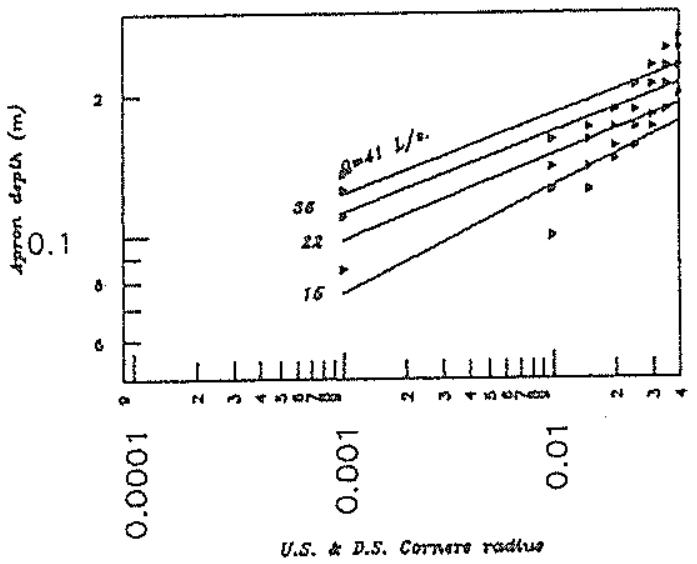

Fig.(6-6) Relationship between Apron Length vereus orest hsight and $(Q)$ as a third dimension 
تأثير الخصائص الهندسية للهار عريض المتب على أبعاد الفرش الغزلقي

\author{
د/ قاسم صلامح عبد الوهاب الألفي ، د/ مصطفى عباس أحمد العناني \\ كلية الهنلسة بشيبين الكوم - قسمر الهنفسة المدلية
}

يتناول البحث دراسة تجريبية معملية لتأثير الحخصسائص الفنلدسية للهسدار عويس العتسب

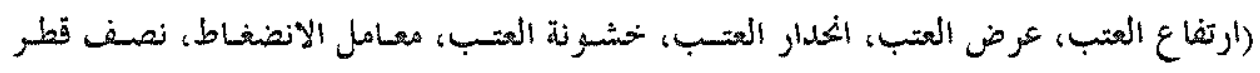

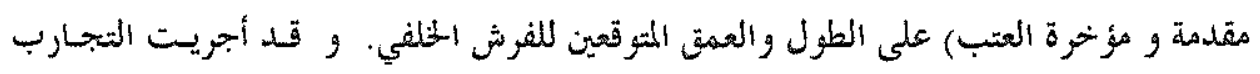
باستخدام نماذج من خشب الزان ذات خصائص هندسية طبقا لكل ثتربة وتم تفير التصريف أربع

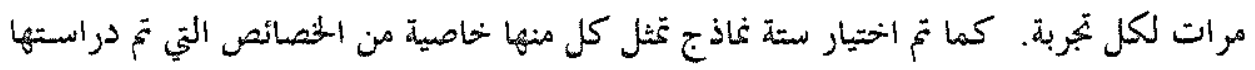
و أعيد بناؤها مع وضع فرش صلب في الحلف بالمحصائص التتي تم تعينها معمليا و تم التشسفيل

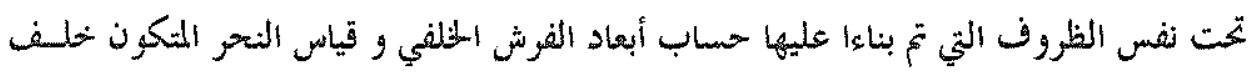
ذلك الفرش.

من تحليل النتائج المعملية وجلد أنه يوبجد ازدياد في الطوله و العمق المثتقع للفـرش مـع

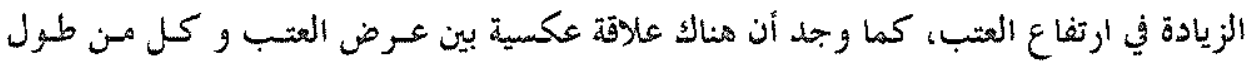
وعمت الفرش. ومن المنتائج أيضا تبين أنه توجد علاقة طردية بين زاوية الخدلار الفتب و كل مسن

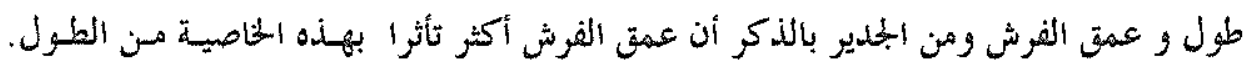

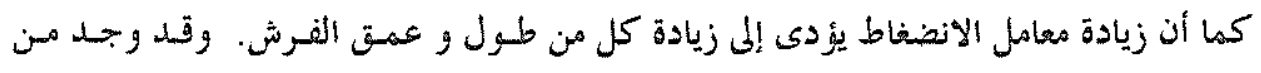

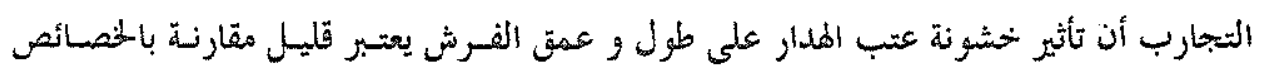

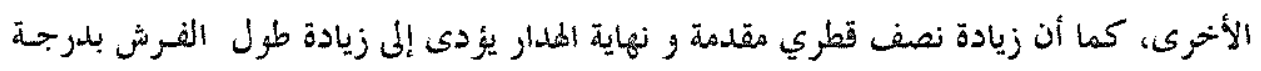

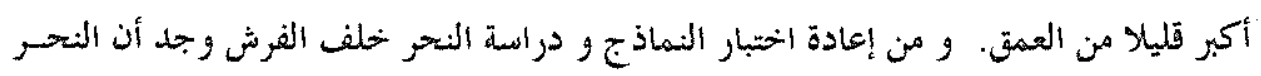
يقل بلدرجة عالية عما هو قبل وضسع الفـرش. كمسا تم استنباط المعـادلات التي تحسبب الطول

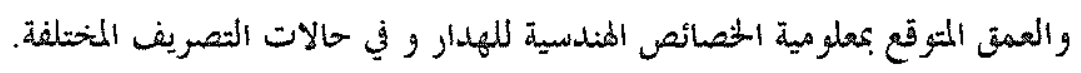

